\title{
ADVOCACIA PÚBLICA: ÓRGÃO DO ESTADO OU DO PODER EXECUTIVO? ${ }^{1}$
}

\author{
Claudio Penedo Madureira ${ }^{2}$
}

\begin{abstract}
Resumo
Este trabalho tem por objetivo demonstrar que as procuradorias públicas não se apresentam como órgãos do Poder Executivo, qualificando-se, em verdade, como órgãos de Estado, aqui considerado em sentido mais amplo. Para atingi-lo, parto do posicionamento da Advocacia Pública na organização do Estado Brasileiro e da especificação das atribuições conferidas pelo constituinte a cada uma das instituições públicas que integram o rol das chamadas funções essenciais da justiça, para discorrer sobre as dificuldades inerentes à designação das procuradorias públicas como órgãos subordinados ao Poder Executivo e sobre a consequente necessidade da sua qualificação como órgãos constitucionais de soberania. A confirmação da tese segundo a qual a Advocacia Pública transcende a estrutura do Poder Executivo, para se configurar como órgão de Estado, refuta a ilação (colhida da práxis jurídica) de que seus integrantes estariam obrigados a procurar conferir aparência de legalidade a opções políticas e administrativas preconcebidas pelos governantes e demais gestores públicos, e com isso confere maior efetividade ao controle interno da atividadeadministrativa.
\end{abstract}

Palavras-chaves: Direito. Direito Constitucional. Direito Administrativo. Advocacia Pública. Órgãos constitucionais de soberania.

\section{EXPOSIÇÃO DO PROBLEMA.}

Por ocasião do julgamento da Ação Direta de Inconstitucionalidade no 470, em que o Supremo Tribunal Federal discutiu a constitucionalidade de dispositivo da Constituição do Estado do Amazonas que atribuiu autonomia funcional à Procuradoria daquele Estado em moldes semelhantes aos especificados pela Constituição da República para o Ministério Público, o Ministro Ilmar Galvão fundou o seu convencimento no sentido da impossibilidade da extensão dessa prerrogativa aos procuradores na circunstância de a Advocacia Pública qualificar-se como "órgão hierarquicamente subordinado ao Governador do Estado"3 e exercer "atividade cuja parcialidade é necessária e que exige perfeita sintonia com as diretrizes fixadas pela Chefia da Administração

\footnotetext{
${ }^{1}$ Este trabalho foi concebido no contexto de pesquisa financiada pela Fundação de Amparo à Pesquisa e Inovação do Espírito Santo - FAPES (Edital no 06/2015 - UNIVERSAL INDIVIDUAL), que estuda "A conciliação como meio alternativo para a resolução de controvérsias jurídicas envolvendo a Fazenda Pública”.

${ }^{2}$ Doutor em Direito pela PUC/SP, Mestre em Direito Processual pela UFES, Professor do Programa de Pós-Graduação em Direito da UFES (Mestrado em Direito).E-mail:madureira.fmr@gmail.com

3 "A controvérsia dos autos resume-se, assim, em determinar se tal prerrogativa é compatível com a advocacia pública desempenhada pelos Procuradores do Estado do Amazonas, que compõem órgão hierarquicamente subordinado ao Governador do Estado e integrante da Administração Pública Estadual, sendo responsável por seu assessoramento jurídico”.
} _vol.09, nº. 02, Rio de Janeiro, 2016. pp. 1155-1174 
Pública”ł. Para além de tecer essas considerações, Galvão faz referência expressa ao posicionamento fixado pelo Tribunal Constitucional em julgamento anterior, proferido quando da concessão de Medida Cautelar na Ação Direta de Inconstitucionalidade no 291. Nesse processo, o Ministro Moreira Alves referiu às "questões que podem surgir, inclusive de imediato, para a boa marcha da Administração do Estado em virtude do desvinculamento dos seus órgãos de defesa com relação ao Chefe do Poder Executivo" para negar autonomia funcional à Advocacia Pública. Em mesmo sentido se posicionou, na oportunidade, o Ministro Sepúlveda Pertence, que sintetizou, nos termos seguintes, a objeção imposta pelos Ministros da Suprema Corte a partir de então, nesse e em outros julgamentos ${ }^{5}$, ao reconhecimento de autonomia funcional aos procuradores, e que se instrumentaliza na distinção entre os âmbitos de atuação da Advocacia Pública e do Ministério Público:

"Quando assumi a Procuradoria-Geral da República, lembro-me de que me referi ao dilema
institucional vivido, cotidianamente, pelo seu titular, que exerce, de um lado, as funções de
chefe do Ministério Público, a reclamar-lhe isenção e independência, em relação,
particularmente, ao Governo; e de outro, de chefe da advocacia contenciosa da União,
função a demandar uma relação de estrita confiança. Só a cisão orgânica das duas funções, na
Constituição de 88 , permitiu dotar o Ministério Público das garantias de que hoje dispõe, de
uma verdadeira 'magistratura requerente', para usar a expressão do DireitoItaliano.
Creio que transplantar essas garantias e esses princípios adequados ao Ministério Público à
advocacia do Estado é institucionalmente tão esdrúxulo quanto, anteriormente, em função
mesmo de acumular estas funções, era desastroso negar ao Ministério Público as garantias
fundamentais ao exercício de suas funçõesespecíficas".

Vê-se, pois, que o Excelso Pretório parece vincular, nesses julgamentos, a atuação das procuradorias públicas à defesa das opções políticas e administrativas manifestadas pelo Chefe do Poder Executivo e pelos órgãos estatais que seus integrantes atendem. Talvez por esse motivo a legislação infraconstitucional de um modo geral confira status de Ministros ou de Secretários aos seus dirigentes ${ }^{6}$, opção político-legislativa que sugere que a Advocacia Pública integra, como órgão jurídico, a estrutura administrativa do Poder Executivo.

No entanto, essa afirmação vai de encontro a entendimento firmado mais recentemente pelo Supremo Tribunal Federal, que, apreciando mandados de segurança impetrados contra decisões do Tribunal de Contas da

\footnotetext{
4"Evidente, dessa forma, a incompatibilidade entre autonomia funcional e o mister desenvolvido pelos Procuradores do Estado, que, nos termos do art. 132 da Constituição exercem a representação judicial e a consultoria jurídica das respectivas unidades federadas, em atividade cuja parcialidade é necessária e que exige perfeita sintonia com as diretrizes fixadas pela Chefia da Administração Pública".

${ }^{5}$ Vide STF, ADIN nº 217, Relator Ministro Ilmar Galvão; STF, ADIN nº 2.581, Relator Ministro Maurício Correa; STF, ADIN nº 291, Relator Ministro Joaquim Barbosa.

${ }^{6}$ Tal se verifica em âmbito federal desde que a Lei no 10.869/2004 modificou a Lei no 9.649/1998, acrescentando-lhe o artigo 24$\mathrm{B}$, que concedeu o status de ministro de Estado, entre outras autoridades administrativas, ao Advogado Geral da União. Em âmbito estadual, atribuem ao Procurador Geral do Estado prerrogativas semelhantes àquelas conferidas aos Secretários os Estados do Acre (CEAC, art. 124), do Amapá (CEAP, art. 153, p. 1º), do Amazonas (CEAM, art. 96, p. 1º), do Espírito Santo (LCE 88, art. $5^{\circ}$ ), de Goiás (CEGO, art. 118, p. 1; LCE 58, art. 4), do Maranhão (CEMA, art. 108), do Mato Grosso (LCE 111, art. 6º), do Mato Grosso do Sul (LCE 95, art. 4ํ, p. 1), do Pará (LCE 41, art. 40), Paraíba (CEPB, art. 132), Paraná (CEPR, art. 126), Piauí (CEPI,

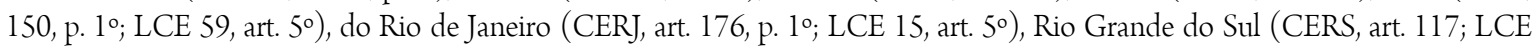
11.742, art. 10), do Rondônia (LCE 620, art. $2^{\circ}$ ), de Roraima (LCE 71, art. 4º p. único), de Santa Catarina (CESC, art. 103, p. 1º), de São Paulo (CESP, art. 100, p. único) e de Sergipe (CESE, art. 120, p. 1; LCE 27, art. 6º p. único), bem como o Distrito Federal (LCD 395, art.30).
} 
União que dispunham sobre a extensão do seu controle externo a pareceres exarados por procuradores, reviu seu posicionamento anterior, no sentido da inviabilidade da responsabilização desses profissionais por suas manifestações jurídicas ${ }^{7}$, e passou a entender que os procuradores, quando exaram pareceres vinculantes, podem vir a ser responsabilizados por esses seus opinamentos ${ }^{8}$. O ponto de vista assumido nessas manifestações pretorianas é o de que os advogados públicos, quando exaram manifestações vinculantes, participam da construção da vontade administrativa (cf. Madureira, 2015, p. 98-99), e por isso podem vir a ser responsabilizados pessoalmente quando seus pareceres não podem deixar de ser atendidos pelos governantes e pelos demais agentes públicos. Destarte, se, para o Excelso Pretório, determinadas manifestações exaradas por procuradores não podem ser descumpridas, é natural que se conclua, com base nesses mesmos precedentes, que esses opinamentos são lavrados com a necessária independência em relação àqueles que comandam a Administração Pública. Assim não fosse não haveria pareceres vinculantes, como assentou o Tribunal Constitucional, pois seria suficiente à sua inobservância simples determinação aos procuradores para que os modificassem, de modo a adequá-los aos desígnios pessoais e/ou políticos dos governantes ou de outros agentes públicos que ocupam posições de gestão na Administração. Enfim, ou os procuradores podem manifestar-se em desconformidade com opções políticas e administrativas preconcebidas pelos gestores públicos, ou não se cogita, em qualquer hipótese, da sua responsabilização nos moldes aventados pela Suprema Corte nesses julgamentos.

Disso resulta a importância de discutir, no plano da Ciência, sobre se de fato a Advocacia Pública se apresenta como órgão subordinado à Chefia do Poder Executivo, porque tem atuação marcada pela parcialidade referida pelo Ministro Ilmar Galvão por ocasião do julgamento da Ação Direta de Inconstitucionalidade no 470, sobre se efetivamente a sua desvinculação dos interesses defendidos pelo Chefe do Executivo prejudicaria a boa marcha da Administração do Estado, como destacou o Ministro Morteira Alves no contexto do julgamento da Ação Direta de Inconstitucionalidade no 291, e sobre se, com isso, as procuradorias devem obrigatoriamente manter relação de estrita confiança com o Chefe do Executivo, como observou o Ministro Sepúlveda Pertence nesse último julgamento. Em específico, é relevante investigar se a Advocacia Pública se apresenta como órgão do Poder Executivo, ou se ela qualifica, em vez disso, como órgão de Estado, aqui considerado em sentido mais amplo. A isso me proponho neste artigo, em que parto do posicionamento da Advocacia Pública na organização do Estado Brasileiro (tal como delineada pelo texto constitucional) e da especificação das atribuições conferidas pelo constituinte a cada uma das instituições públicas que integram o rol das chamadas funções essenciais da justiça (qualificadas por Diogo de Figueiredo Moreira Neto como Procuraturas Constitucionais), para discorrer sobre as dificuldades inerentes à designação das procuradorias como órgãos subordinados ao Poder Executivo e

\footnotetext{
${ }^{7}$ Retratado, exemplificativamente, no julgamento do Mandado de Segurança no 24.073, relatado pelo Ministro Carlos Veloso (STF, MS 24.073/DF, Relator Ministro Carlos Velloso, Julgamento: 06/11/2002, Tribunal Pleno, Publicação DJ 31-10-2003). ${ }^{8}$ Refiro-me, nesse ponto, ao julgamento dos Mandados de Segurança no 24.584 e 24.631, relatados, respectivamente, pelos Ministros Marco Aurélio e Joaquim Barbosa.
} vol.09, no. 02, Rio de Janeiro, 2016.pp. 1155-1174 
sobre a consequente necessidade da sua qualificação como órgãos constitucionais de soberania (qualificação proposta por Canotilho para distinguir determinados órgãos públicos que têm competências fixadas na Constituição, que dispõem de certo poder de auto-organização interna, que não estão subordinados a outros órgãos e que com eles estabelecem relações de interdependência e controle).

\section{POSICIONAMENTO DA ADVOCACIA PÚBLICA NA ORGANIZAÇÃO DO ESTADO BRASILEIRO.}

A Advocacia Pública mereceu do constituinte tratamento normativo específico, que se revela na sua inserção no Título IV da Constituição de 1988, que trata "Da Organização dos Poderes". Constam desse título, capítulos dedicados aos Poderes Legislativo (Capítulo I), Executivo (Capítulo II) e Judiciário (Capítulo III), assim como o Capítulo IV, consagrado às chamadas "Funções Essenciais da Justiça”. Esse último capítulo alberga o Ministério Público (Seção I), a Advocacia Pública (Seção II), a Advocacia Privada e a Defensoria Pública (Seção III) (cf. Carpes, 2009, p. 213)9.

Vê-se, pois, que o constituinte não situou a Advocacia Pública no capítulo que trata do Poder Executivo (Capítulo II do Título IV da Constituição), mas a localizou, ao lado do Ministério Público, da Advocacia e da Defensoria Pública, entre as chamadas "Funções Essenciais da Justiça" (Capítulo IV do Título IV da Constituição) (cf. Di Pietro, 1996, p. 13). Essa opção político-normativa não pode ser menosprezada quando se indaga sobre o posicionamento da Advocacia Pública no EstadoBrasileiro.

Assume relevo, nesse contexto, a topologia da sua inserção na organização dos poderes no texto da Carta da República. Assim o destaca, em doutrina, Juan Pablo Couto de Carvalho, quando aduz que "a topologia das normas no bojo da CF/88 revela a situação diferenciada da Advocacia do Estado", à consideração de que o constituinte originário conferiu a ela "locus próprio dentro do Capítulo das 'Funções Essenciais à Justiça”, emerso, portanto, "fora das prateleiras do 'Poder Executivo', do 'Poder Legislativo' e do 'Poder Judiciário”' (2009, p. 437). Nesse mesmo sentido se posicionou o Ministro Dias Tofolli, do Supremo Tribunal Federal, em Voto proferido por ocasião do julgamento do Recurso Extraordinário no $558.258^{10}$. Na oportunidade, Tofolli assentou que a Advocacia Pública, como o Ministério Público e a Defensoria Pública, não integra nenhum dos Poderes da

\footnotetext{
${ }^{9}$ Essa particularidade do regramento constitucional das funções essenciais à justiça não escapou à arguta percepção de Maria Sylvia Zanella Di Pietro, que a aponta na seguinte passagem doutrinária: "É interessante notar que, embora a Constituição adote, no artigo 2º o princípio da separação entre os Poderes, ela prevê, no Título IV, denominado de 'Organização dos Poderes', quatro e não três capítulos; os três primeiros pertinentes a cada um dos Poderes do Estado; e, o quarto, imediatamente seguinte ao que cuidado do Poder Judiciário, referente às "Funções Essenciais à Justiça”, nele incluindo o Ministério Público, a Advocacia Geral da União, a Advocacia, a Defensoria Pública e a Procuradoria Geral do Estado” (1996, p. 13).

${ }^{10}$ Julgado que versa sobre o teto remuneratório dos "procuradores autárquicos" do Estado de São Paulo (STF, RE 558258/SP, Relator Ministro Ricardo Lewandowski, Julgamento: 09/11/2010, Órgão Julgador: Primeira Turma, Publicação: DJe-051 DIVULG 17-03-2011 PUBLIC 18-03-2011 EMENT VOL-02484-01 PP-00188).
} 
República (Executivo, Legislativo e Judiciário), dispondo textualmente que essa instituição, "no texto constitucional, [...] não está dentro do Poder Executivo”. Exemplificando, Toffoli também observa, em vista da estrutura da Advocacia Pública Federal, que "se formos analisar a Advocacia Geral da União, a lei de organização do Poder Executivo não faz referência a ela”, mas apenas ao Advogado Geral da União; e por isso acrescenta que "quem integra o Poder Executivo, única e exclusivamente, é o Advogado Geral da União, e não a Advocacia Geral da União"; advertindo, a propósito, que "nem poderia ser diferente, porque, no texto constitucional, ela não está dentro do Poder Executivo".

Também deve ser destacado, no pormenor, o emprego pelo constituinte das expressões essenciais e justiça. Afinal, como cediço, a lei e a Constituição nãocontêm palavras inúteis.

Sobre serem essenciais os órgãos de advocacia pública, Carvalho observa que "a palavra essencial há de ter significado jurídico" para a descrição do posicionamento da Advocacia Pública no Estado Brasileiro, à consideração de que a "essencialidade repugna a subordinação a outra função do Estado" (2009, p. 438). Assim, adverte o publicista, a Advocacia Pública "não é essencial ao Poder Executivo", mas "função essencial ao Estado Democrático de Direito, tanto quanto o Poder Executivo (e outras tantas funções) pode sê-lo” (Carvalho, 2009, p. 438).

Sobre serem essenciais à justiça, Mário Bernardo Sesta expressa que a alocação dessas instituições, "na topologia da constituição, de forma inteiramente nova no constitucionalismo brasileiro, e sua qualificação como 'funções essenciais à Justiça' está a significar que participam da essência da atividade de realização da Justiça” (1993, p. 72). Conforme Sesta, resulta dessa sua qualificação constitucional o entendimento de "que, sem seu concurso, justiça não haverá, pressuposto e decorrência que são da escolha constitucional de um perfil moderno de Estado Democrático" (1993, p. 72). Essa opção político-normativa significa, para Sesta, a "sobrevalorização do interesse público", que se busca alcançar, no regime da Carta de 1988, não mais apenas "pela pacificação vinculativa na solução das lides, mas ainda por uma especial valorização da custodia da lei", que resulta, quando se tem em vista especificamente o feixe de atribuições conferidas pelo ordenamento jurídico-positivo aos advogados públicos, da "impessoalidade no aconselhamento preventivo e no patrocínio judicial dos interesses do Estado" (1993, p.72).

Assim, os advogados públicos são essenciais à realização da justiça porque contribuem para a aplicação do Direito nos processos judiciais, contexto em que se apresentam como partícipes da atividade cognitiva desenvolvida pelos órgãos jurisdicionais ${ }^{11}$. Com efeito, na lição de Maria Sylvia Zanella Di Pietro, "na medida em

\footnotetext{
${ }^{11}$ Quanto ao pormenor, reporto-me às considerações de Daniel Mitidiero quando descreve, em doutrina, "o modelo de processo corresponde ao processo cooperativo, pautado pelo diálogo judiciário, pela colaboração e pela lealdade entre as pessoas que participam do processo" (MITIDIERO, Daniel Francisco. Colaboração no processo civil: pressupostos sociais, lógicos e éticos. São Paulo: Revista dos Tribunais, 2009. p. 17). Como sustentei em trabalho anterior, esse modelo teórico qualifica o processo _vol.09, nº. 02, Rio de Janeiro, 2016.pp. 1155-1174 
que os conflitos de interesses têm de ser levados ao Judiciário necessariamente por meio de advogado, a ele cabe a tarefa de lutar pela correta aplicação do Direito, seja por parte de particulares, seja pelos Poderes instituídos” (1996, p. 14). Em sentido mais amplo, "a advocacia postulatória é a expressão privativa das funções essenciais à justiça, destinando-se a suscitar a atuação de qualquer dos Poderes do Estado, em especial o Judiciário, para a correção da injuridicidade", como observa, em doutrina, Diogo de Figueiredo Moreira Neto (1991, p. 21).

São também essenciais à justiça porque desempenham, em sede administrativa, atividade interpretativa concretizadora correlata àquela desenvolvida pelos juízes ${ }^{12}$, contexto em que, aplicando corretamente o Direito, fazem justiça ao cidadão, seja ao que articula pretensões administrativas em face do poder público, seja àquele que simplesmente suporta a sua atividade administrativa, cuja incidência, por óbvio, não pode ultrapassar os limites impostos pelo ordenamento à intervenção do Estado na esfera das suas disponibilidades jurídicas (cf. Madureira, 2015, p. 34-38). Conforme Moreira Neto, "a advocacia consultiva é a expressão preventiva dessas funções, destinando-se a evitar o surgimento ou a permanência de agressão à ordem jurídica - a injuridicidade - como quer que ela se apresente, decorra de ação ou de omissão, na órbita privada ou pública” (1991, p. 21).

O seu enquadramento constitucional como função essencial da justiça, quando conjugada a essas particularidades de sua missão institucional, permite entrever que a Advocacia Pública, mesmo quando estruturada, sob o ponto de vista da organização administrativa, como órgão da Administração Direta das unidades federadas, não se apresenta como órgão executivo ${ }^{13}$, ou como órgão do Poder Executivo; despontando, em rigor, como órgão autônomo, a exemplo do Ministério Público, da Defensoria Pública (esses últimos integrantes das funções essenciais da justiça) e dos Tribunais de Contas (que auxiliam o Poder Legislativo das unidades federadas no controle externo da atividade legislativa); porque exerce (ou, pelo menos, está habilitada a exercer), pela via do desempenho de suas atividades consultivas e contenciosas (arts. $131^{14} \mathrm{e} 132^{15}$ ), o controle interno da juridicidade do agir administrativo (art. 70 ${ }^{16}$ ) (cf. Madureira, 2015, p. 102-106 e340-342).

como ambiente dialógico e democrático por excelência, conferindo a ele (processo) a qualidade de mediador adequado entre o direito e a justiça" (Madureira, 2013, p.283).

${ }^{12}$ Ao ensejo, José Joaquim Gomes Canotilho ensina que "para se passar da normatividade mediata para a normatividade concreta, a norma jurídica precisa de revestir o caráter da norma de decisão", o que se faz por meio de processo de concretização normativa, que, para Canotilho, não se restringe ao campo do controle judicial (2000, p. 1.221). Conforme Canotilho, uma norma jurídica adquire verdadeira normatividade a medida de ordenação nela contida induza a decisão de um caso jurídico, isto é, quando o processo de concretização da norma se completa por meio da sua aplicação ao caso jurídico; o que pode se dar (i) pela criação de uma disciplina regulamentadora (concretização legislativa, regulamentar), no corpo de sentenças ou decisões judiciais (concretização judicial), e também através da prática de atos individuais por autoridades administrativas (concretização administrativa) (2000, p. 1.221). Sobre o assunto, ler também: Madureira, 2015, p.287-288.

${ }^{13}$ Assim entendidos os órgãos responsáveis pela execução de políticas públicas ditadas pela equipe de Governo.

${ }^{14} \mathrm{CRFB}$. "Art. 131. A Advocacia-Geral da União é a instituição que, diretamente ou através de órgão vinculado, representa a União, judicial e extrajudicialmente, cabendo-lhe, nos termos da lei complementar que dispuser sobre sua organização e funcionamento, as atividades de consultoria e assessoramento jurídico do Poder Executivo".

${ }^{15} \mathrm{CRFB}$. "Art. 132. Os Procuradores dos Estados e do Distrito Federal, organizados em carreira, na qual o ingresso dependerá de concurso público de provas e títulos, com a participação da Ordem dos Advogados do Brasil em todas as suas fases, exercerão a vol.09, no. 02, Rio de Janeiro, 2016.pp. 1155-1174 


\section{AS PROCURATURAS CONSTITUCIONAIS E SUAS RESPECTIVAS FUNÇÕES INSTITUCIONAIS.}

Diogo de Figueiredo Moreira Neto sublinha a relevância de o constituinte haver concebido, no Título consagrado à "Organização dos Poderes”, além dos capítulos dedicados aos três Poderes da República (Executivo, Legislativo e Judiciário), um quarto capítulo cuidando das chamadas "Funções Essenciais à Justiça” (1991, p. 11). Essa opção política decorre, para esse professor fluminense, de "um milenar processo evolutivo", no curso do qual "com crescente nitidez, vão-se distinguindo funções específicas" (Moreira Neto, 1991, p. 17) ${ }^{17}$. Nesse processo, destacaram-se, num primeiro momento, as funções legislativa, executiva e jurisdicional; sendo que só mais recentemente é que obteve relevo, como resultado dos "últimos avanços da teoria constitucional", a chamada função de controle, "para o exercício da qual concorrem todos os Poderes e a própria sociedade" (Moreira Neto, 1991, p. 17). O que se dá é que, conforme Moreira Neto, o Estado e a sociedade "exercem multímodos e recíprocos papéis de controlados e controladores", precisamente porque a Constituição distribuiu entre eles "inúmeras funções de fiscalização, de provocação e de correção" (1991, p. 17). Em tal conjuntura, "os três Poderes tradicionais, principalmente o Poder Judiciário, têm a seu cargo a correção", ao passo que "as funções essenciais à justiça e a sociedade, cuidam da fiscalização e da provocação" (Moreira Neto, 1991, p. 17-18).

Esse novo esquema de distribuição de poderes, conquanto mantenha nos poderes tradicionais o seu mais importante centro de decisão sobre a juridicidade, singulariza-se pela descentralização dessa atividade "nas funções essenciais à justiça, nos indivíduos, nas empresas, nas associações e nas instituições privadas, em geral" (Moreira Neto, 1991, p. 18). Nessa perspectiva, as chamadas funções essenciais à justiça comportam o que Moreira Neto designou como um "conjunto de atividades políticas preventivas e postulatórias através das quais interesses juridicamente reconhecidos são identificados, acautelados, promovidos e defendidos por órgãos tecnicamente habilitados, sob garantias constitucionais" (1991, p. 20); contexto em que, prossegue o publicista, "a advocacia privada volta-se preferente, ainda que não exclusivamente, à defesa dos interesses individuais, coletivos e difusos da sociedade", e é "praticada por profissionais de direito, em caráter contratual" (1991, p. 23); ao passo que "a advocacia pública destina-se à defesa dos interesses públicos, bem como dos interesses individuais, coletivos e

representação judicial e a consultoria jurídica das respectivas unidades federadas. (Redação dada pela Emenda Constitucional no 19, de 1998)".

${ }^{16}$ CRFB. "Art. 70. A fiscalização contábil, financeira, orçamentária, operacional e patrimonial da União e das entidades da administração direta e indireta, quanto à legalidade, legitimidade, economicidade, aplicação das subvenções e renúncia de receitas, será exercida pelo Congresso Nacional, mediante controle externo, e pelo sistema de controle interno de cada Poder".

${ }^{17}$ Quanto ao particular, Ronny Charles Lopes de Torres expressa que essa "distribuição ordenada pela Constituição tem sentido e propósito", vez que "o constituinte, ao assim estabelecer, demonstrou sintonia com as mudanças que refletiram no Estado Moderno e que tornaram inadequada ou insuficiente a teoria da separação dos poderes, em sua compleição original” (2009, p. 116141$).$ 


\section{Quaestio Iuris}

vol. 09, nº. 02, Rio de Janeiro, 2016. pp. 1155-1174

DOI: $10.12957 /$ rqi.2016.19983

difusos que a ordem jurídica lhe cometer", e é praticada por profissionais de direito que se investem da condição de agentes públicos, que se organizam nas procuradorias públicas, qualificadas por Moreira Neto como Procuraturas Constitucionais (1991, p.23).

Observe-se, contudo, que Moreira Neto designa como procuraturas não apenas os órgãos de representação jurídica das unidades federadas, mas toda e qualquer instituição que desempenha, em suas palavras, um ministério público $\left(1991\right.$, p. 23) ${ }^{18}$. Para esse professor fluminense, a Constituição criou três diferentes tipos institucionais de procuraturas encarregadas das funções essenciais à justiça, que exercem "atribuições consultivas e postulatórias, todas bem definidas a nível constitucional (arts. 127, 129, 131, 132, 133 e 134, CF) e infraconstitucional (Constituições estaduais e respectivas leis orgânicas), voltadas a três conjuntos de interesses caracterizados" (Moreira Neto, 1991, p. 23-24).

Moreira Neto destaca um primeiro conjunto de interesses, que abrange "os interesses difusos da defesa da ordem jurídica e do regime democrático e os interesses sociais e individuais indisponíveis (art. 127, caput, da Constituição)", que foram “detalhados em rol de funções (art. 129, CF), em relação aberta, pois pode ser acrescida de outras funções, desde que compatíveis com a finalidade institucional (art. 129, IX)” (1991, p. 24). E observa que "a função essencial à justiça que lhe corresponde é a advocacia da sociedade", e que "a procuratura que a tem a seu cargo é o Ministério Público, em seus ramos federal, distrital federal e estaduais" (Moreira Neto, 1991, p. 24).

O publicista refere, ainda, como segundo conjunto de interesses, aos "interesses públicos, assim entendidos os estabelecidos em lei e cometidos ao Estado, em seus desdobramentos políticos (União, Estados e Distrito Federal)" (Moreira Neto, 1991, p. 24). E aduz que a função essencial à justiça a ele correspondente "é a advocacia do Estado (art. 131, para a União, e 132, para os Estados e Distrito Federal)", e que "as procuraturas que a tem a seu cargo são a Advocacia Geral da União (órgão coletivo) e os Procuradores dos Estados e do Distrito Federal (órgãos singulares)" (Moreira Neto, 1991, p. 24). A elas acrescento as Procuradorias Municipais, que devem ser instituídas pelos Municípios Brasileiros, por imposição constitucional, como forma de assegurar que o controle da juridicidade do agir administrativo também se realize em âmbito local (cf. Madureira, 2014).

Por fim, alude a um terceiro conjunto de interesses, que se singulariza "pela insuficiência de recursos daqueles que devam ou queiram defendê-los", qualificando-se, portanto, como "interesses dos necessitados" (Moreira Neto, 1991, p. 24). E afirma que a procuratura que tem a seu cargo essa função essencial da justiça "é a Defensoria Pública, federal, distrital federal e estadual (art. 134, CF)” (Moreira Neto, 1991, p. 24).

Apresentadas, nesses termos, as procuraturas constitucionais, e expostas, ainda que sinteticamente, as suas respectivas atribuições, tem-se afirmado, a partir da doutrina de Moreira Neto, que o Ministério Público, a

\footnotetext{
${ }^{18}$ É que, como observa Marcus Ronald Carpes, referindo-se à doutrina de Moreira Neto, "a custódia do interesse público, nas suas variadas facetas, adequando-se às necessárias especificações e capacitações técnicas, visando a preservar o Estado de Direito e alcançar o Estado de Justiça, desdobrou-se no que Moreira Neto definiu como sendo as Procuraturas Constitucionais" (2009, p.
} 
Defensoria Pública e a Advocacia de Estado seriam espécies do gênero Advocacia Pública (cf. Kirch, 2009, p. 396). Não me afeiçoo a essa classificação. Em especial porque, com a edição da Emenda Constitucional no 19, a Constituição da República passou a designar a Seção II do Capítulo IV do seu Título IV, que congrega os órgãos de representação jurídica do Estado, sob a denominação "Da Advocacia Pública". Em vista disso, reputo pertinente, inclusive como forma de se conferir denominação uniforme aos serviços jurídicos instituídos nas três esferas da Federação, a qualificação desses órgãos de representação simplesmente como Advocacia Pública (cf. Grande Jr., 2009, p. 61). Nessa perspectiva, e tendo em vista a doutrina de Moreira Neto, creio ser mais consentânea com as opções político-normativas assimiladas pelo texto constitucional a afirmação de que as procuraturas, qualificadas pelo constituinte como funções essenciais da justiça, constituem gênero do qual são espécies o Ministério Público, a Advocacia Pública e a DefensoriaPública.

Fechado esse parêntese, devo destacar que, conforme Moreira Neto, as procuraturas não integram nenhum dos Poderes (1991, p. 25). Em primeiro lugar porque, "assentado que se tratam de agentes políticos, com autonomia de suas funções", resulta evidente que esses órgãos jurídicos "não poderiam, efetivamente, integrar qualquer dos Poderes", pois a ser de outro modo poderia se verificar em concreto a submissão de suas atribuições "a outros agentes políticos (por exemplo, a assessores e assistentes jurídicos investidos em cargos comissionados) (Moreira Neto, 1991, p. 31). Por isso, as procuraturas comportam "quadros próprios, desvinculados e desarticulados com os quadros de quaisquer dos três Poderes" (Moreira Neto, 1991, p. 31). Ademais, adverte Moreira Neto, inexiste "subordinação hierárquica dos agentes políticos das procuraturas constitucionais a qualquer autoridade dos Poderes Políticos", porque "a hierarquia é estranha à instituição da advocacia", que admite relações legalmente definidas, mas incompatíveis com a subordinação funcional, de modo que "nem mesmo em relação ao chefe dos órgãos coletivos das procuraturas existe hierarquia funcional", mas apenas hierarquia administrativa $\left(1991\right.$, p. 31) ${ }^{19}$.

Trata-se, pois, como destaca César do Vale Kirch, de "um conjunto de instituições que têm as missões de defender interesses públicos, individuais, coletivos e difusos", que se instrumentalizam sob a forma da fiscalização "da ação dos Poderes constitucionalmente estabelecidos, notadamente o hipertrofiado Executivo", como forma de garantir aos administrados que esses poderes "desempenhem de forma regular e eficiente suas respectivas atividades" (2009, p. 396). Disso decorre a sua qualificação por Kirch como "instituições com a mesma essência, embora com 'clientes' diferentes", que desenvolvem "atividades consultivas e postulatórias", e são "responsáveis

\footnotetext{
${ }^{19}$ A propósito, Maria Sylvia Zanella Di Pietro leciona, abordando os limites do poder hierárquico na Administração Pública, que "pode haver distribuição de competências dentro da organização administrativa", com a exclusão "da relação hierárquica com relação a determinadas atividades” (2001, p. 92). Nesse contexto, o exemplo empregado pela professora paulista para demonstrar essa sua afirmação reside precisamente na atuação dos órgãos consultivos, "que, embora incluídos na hierarquia administrativa para fins disciplinares, por exemplo, fogem à relação hierárquica no que diz respeito a suas funções”, por exercerem "determinadas atividades que, por sua própria natureza, são incompatíveis com uma determinação de comportamento por parte do superior hierárquico" (Di Pietro, 2001, p. 92). Sobre o assunto, ler também: Madureira, 2015, p. 243-248.
} 
pela defesa de interesses necessários à existência, à preservação e ao aperfeiçoamento do Estado Democrático de Direito" (2009, p. 396).

Essa forma de dissociação entre os enfoques de atuação de cada procuratura, marcada pela distinção entre os seus "clientes", tem singular importância para a funcionalidade da sua atuação em benefício da preservação e aperfeiçoamento do Estado de Direito. Assim o expressam, em doutrina, Jefferson Carús Guedes e Luciane Moessa de Souza quando dispõem que a partir da especialização de funções entre Advocacia Pública e o Ministério Público "criou-se um espaço para aperfeiçoamento da missão de ambas as instituições", num contexto em que a Advocacia Pública "passa a ter condições de aprimorar o controle preventivo de licitude dos atos da Administração Federal, bem como, mais recentemente, de atuar de forma pró-ativa na esfera contenciosa", cumprindo ao Ministério Público ir além de sua atuação na esfera criminal e assumir "o papel efetivo de defensor da sociedade na esfera dos direitos coletivos em sentido amplo" (2009, p. 17).

\section{DIFICULDADES INERENTES À QUALIFICAÇÃO DA ADVOCACIA PÚBLICA COMO ÓRGÃO SUBORDINADO AO PODER EXECUTIVO.}

Estou de pleno acordo com a afirmação de Diogo de Figueiredo Moreira Neto quanto a não se subordinarem as procuraturas a nenhum dos Poderes da República (1991, p. 25); a que também aderem Sérgio de D 'Andréa Ferreira (1991, p. 12), Maria Jovita Wolney Valente (2009, p. 364), Valdemar Leite (2003, p. 93-94), Rommel Macedo (2008, p. 161) e César do Vale Kirch (2009, p. 398), entre outros ${ }^{20}$. Aliás, a Comissão Nacional da Advocacia Pública instituída no âmbito do Conselho Federal da Ordem dos Advogados do Brasil editou, quanto a esse particular, verbete de súmula que expressa que os procuradores apenas se vinculam ao órgão jurídico que integram (portanto, às suas respectivas procuradorias) e que considera inconstitucional qualquer outro tipo de subordinação desses profissionais ${ }^{21}$. Assim não fosse, o constituinte não haveria tido o cuidado de discipliná-las em capítulo autônomo do Título IV da Constituição de 1988 ("Da Organização dos Poderes"), mais especificamente no seu Capítulo IV ("Das Funções Essenciais da Justiça”), portanto fora dos capítulos dedicados aos Poderes Legislativo (Capítulo I), Executivo (Capítulo II) e Judiciário (Capítulo III) 22.

\footnotetext{
${ }^{20}$ Em sentido contrário se manifestam, entre outros, Celso Ribeiro Bastos e Ives Gandra Martins (1997.p.05).

${ }^{21} \mathrm{OAB} /$ Conselho Federal/Comissão Nacional da Advocacia Pública. "Súmula 3 - A Advocacia Pública somente se vincula, direta e exclusivamente, ao órgão jurídico que ela integra, sendo inconstitucional qualquer outro tipo de subordinação” (Disponível na internet: <http://www.oab.org.br/noticia/24762/conselho-federal-traca-diretriz-em-defesa-da-advocacia-publica>; acesso em 22 de maio de 2014).

${ }^{22}$ Ao ensejo, Danilo Cruz Madeira leciona que "por princípio hermenêutico, é sabido que nenhuma disposição legal, ainda mais em se tratando de norma constitucional, deve ser tratada como inútil”, o que torna "imperioso concluir que não foi por acaso que a Constituição da República brasileira decidiu situar as funções essenciais à justiça fora da organização dos demais poderes” (2010, p. 11).
} 
Essa premissa teórica permite concluir que os órgãos de advocacia pública, conquanto em geral componham a estrutura administrativa dos Executivos das unidades federadas ${ }^{23}$, não se encontram juridicamente subordinados a esse Poder da República. Afinal, a circunstância de o constituinte deles não haver se ocupado no capítulo relativo ao Poder Executivo (Capítulo II do Título IV da Constituição), posicionando-os, na topologia da organização dos poderes, entre as chamadas "Funções Essenciais da Justiça" (Capítulo IV do Título IV da Constituição), portanto ao lado do Ministério Público e da Defensoria Pública, os aproxima dessas duas outras procuraturas constitucionais, distanciando-os, por conseguinte, dos órgãos subordinados que compõem o Executivo.

Essa conclusão é corroborada, ainda, pela circunstância de as atividades jurídicas desenvolvidas pela Advocacia Pública não se restrigirem ao âmbito do Poder Executivo. É que compete a esses serviços jurídicos exercer o contencioso judicial não apenas do Executivo, mas também dos Poderes Legislativo e Judiciário, bem como do Ministério Público, da Defensoria Pública e dos Tribunais de Contas; pois a Constituição da República Thes confere a representação jurídica do Estado; donde se conclui que esses poderes e órgãos, porque integram a Administração Pública Direta e, portanto, o Estado, são atendidos pela Advocacia Pública nos processos judiciais de seu interesse (cf. Madureira, 2015, p. 110-117). Em rigor, mesmo a atividade consultiva desenvolvida em favor do Poder Legislativo e do Poder Judiciário (que são independentes do Executivo), assim como do Ministério Público, da Defensoria Pública e dos Tribunais de Contas (que são órgãos autônomos em relação ao Executivo), pode vir a ser desempenhada por essas procuradorias públicas, bastando-se, para tanto, que as Constituições dos Estados e as Leis Orgânicas dos Municípios, seguindo o modelo ditado pelo artigo 132 da Constituição da República, não restrinjam o exercício dessa atividade consultiva ao Executivo ${ }^{24}$. Disso se verifica que os órgãos

\footnotetext{
${ }^{23}$ Cf. Lei Federal no 9.649/1998, art. 24-B (redação dada pela Lei no 10.869/2004), que concedeu o status de ministro de Estado, entre outras autoridades administrativas, ao Advogado Geral da União. Cf., ainda, as disposições normativas que atribuem aos respectivos Procuradores Gerais dos Estados prerrogativas semelhantes àquelas conferidas aos Secretários pelos Estados do Acre (CEAC, art. 124), do Amapá (CEAP, art. 153, p. 1º), do Amazonas (CEAM, art. 96, p. 1º), do Espírito Santo (LCE 88, art. 5), de Goiás (CEGO, art. 118, p. 1; LCE 58, art. 4º), do Maranhão (CEMA, art. 108), do Mato Grosso (LCE 111, art. $6^{\circ}$ ), do Mato Grosso do Sul (LCE 95, art. 4º p. 1º), do Pará (LCE 41, art. 4º), Paraíba (CEPB, art. 132), Paraná (CEPR, art. 126), Piauí (CEPI, 150, p. 1; LCE 59, art. 5o), do Rio de Janeiro (CERJ, art. 176, p. 1; LCE 15, art. 5o), Rio Grande do Sul (CERS, art. 117; LCE 11.742, art. 10), do Rondônia (LCE 620, art. 2º), de Roraima (LCE 71, art. 4º p. único), de Santa Catarina (CESC, art. 103, p. 1º), de São Paulo (CESP, art. 100, p. único) e de Sergipe (CESE, art. 120, p. 1; LCE 27, art. 6º p. único), bem como pelo Distrito Federal (LCD 395, art.30).

${ }^{24}$ Recobro, ao ensejo, que conquanto o constituinte originário tenha restringido a atividade consultiva da Advocacia Geral da União ao âmbito do Poder Executivo (CRFB, art. 131), opção semelhante não foi adotada com relação às Procuradorias dos Estados e do Distrito Federal (CRFB, art. 132), às quais foi conferida "a consultoria jurídica das respectivas unidades federadas", e não meramente dos seus respectivos Poderes Executivos. É certo que, como também assentei, dos vinte e sete Estados que compõem a Federação, vinte e um estabeleceram em suas respectivas Constituições que atividade a consultiva desenvolvida por suas Procuradorias Gerais direciona-se exclusivamente ao Poder Executivo. Porém, em respeito às particularidades do regramento da matéria por seis Estados-Membros (Bahia, Ceará, Mato Grosso, Pará, Piauí e Rio Grande do Sul), e considerando ser possível, em hipótese, que a atividade consultiva tenha sido disciplinada em moldes semelhantes no âmbito de alguns dos milhares de Municípios que integram a Federação, não se pode afirmar, validamente, que a atividade consultiva conferida à Advocacia Pública encontra-se restrita, entre nós, exclusivamente ao âmbito do Executivo (cf. Madureira, 2015, p. 110-117)
} _vol.09, no. 02, Rio de Janeiro, 2016.pp. 1155-1174 
ordinários de advocacia pública ${ }^{25}$ não atendem exclusivamente ao Poder Executivo, mas também atuam em processos de interesse do Poder Legislativo e do Poder Judiciário, bem como do Ministério Público, da Defensoria Pública e dos Tribunais de Contas; qualificando-se, portanto, como órgãos de Estado ${ }^{26}$; o que impede a sua designação como órgãos do Executivo ${ }^{27}$.

Também orienta essa conclusão a imposição constitucional quanto ao estabelecimento, no âmbito interno da Administração, de controle da juridicidade do agir administrativo; atividade típica que decorre naturalmente do exercício da consultoria jurídica e do contencioso judicial, adjudicados à Advocacia Pública pela Carta Política (arts. 131 e 132) (cf. Madureira, 2015, p. 102-106 e 340-342). Trata-se, com efeito, de atividade de controle interno (art. 70), não no sentido de ser exercida no âmago de cada um dos Poderes da República, mas, efetivamente, por consistir no controle da atividade administrativa (portanto, do exercício da função administrativa) pelo órgão instituído para o exercício das atividades jurídicas que possibilitam esse controle. Como o desempenho dessa atividade só é efetivo quando se confere aos órgãos controladores alguma autonomia técnica ${ }^{28}$ (assim não fosse, não se cogitaria de atividade de controle, na medida em que os controlados teriam meios de interferir nas manifestações jurídicas expressadas pelos controladores ${ }^{29}$ ), a subordinação desses serviços jurídicos ao Poder Executivo, assim como a qualquer outro Poder da República, corresponderia a negar a possibilidade de que se estabeleça, em concreto, o controle interno da juridicidade do agir administrativo.

Por tais razões, extraídas, todas elas, de nosso regime constitucional, é impróprio afirmar, mormente com fundamento em opções político-normativas adotadas pelo legislador infraconstitucional, que os órgãos de advocacia pública integram o Poder Executivo, assim como a qualquer outro Poder da República. Em rigor, esses serviços jurídicos apresentam-se, na organização dos poderes, como órgãos dotados de necessária autonomia

\footnotetext{
${ }^{25}$ Compostos pela Advocacia Geral da União e seus órgãos vinculados (CRFB, art. 131), bem como pelas Procuradorias dos Estados e do Distrito Federal e pelas procuradorias municipais (CRFB, art. 132), que não necessariamente incluem as consultorias e procuradorias especiais do Legislativo, do Judiciário e dos precitados órgãos autônomos. E refiro-me nesse ponto a órgãos ordinários de advocacia pública porque é viável entre nós a instituição de procuradorias públicas não previstas pelo constituinte, para atendimento aos Poderes Legislativo e Judiciário e, por interpretação analógica, ao Ministério Público, à Defensoria Pública e aos Tribunais de Contas (cf. Madureira, 2015, p. 110-118).

${ }^{26}$ Conforme César Kirch a Advocacia Pública "tem natureza jurídica de órgão de Estado, constitucionalmente independente e integrante do sistema FEJ, não se vinculando, tampouco se subordinando a qualquer um dos três poderes clássicos” (2009, p. 401). ${ }^{27}$ Assim se posiciona Kirch na seguinte passagem doutrinária: “[... tanto a AGU como as Procuradorias Estaduais e do Distrito Federal têm status constitucional que lhes assegura um claro posicionamento fora das 3 (três) funções clássicas, assim como as suas missões constitucionais típicas de advocacia de Estado e não de Governo destinam-se a atender não só o Executivo, mas também o Legislativo, o Judiciário, os Tribunais de Contas, o Ministério Público e a Defensoria Pública, sendo inadequado e de duvidosa constitucionalidade pretender-se inserir a AGU e as Procuradorias Estaduais e do DF sob o manto do Poder Executivo" (2009, p. 400).

${ }^{28}$ Nesse sentido se manifesta, em doutrina, Marcus Ronald Carpes, quando qualifica a Advocacia Pública como "defensora do patrimônio público, do patrimônio do povo brasileiro", que por isso "não pode, não deve, estar enquadrada dentro de um dos Poderes", por se tratar "de função pública autônoma, independente e destacada das estruturas dos três Poderes do Estado, nos termos da Constituição Federal” (2009, p. 223).

${ }^{29}$ Com efeito, como leciona Carlos Figueiredo Mourão, "o Estado de Direito impõe uma vinculação de toda a atividade estatal à lei”, exigindo, portanto, a instituição de "organismo permanente e equidistante, que não mantenha vínculos com partidos políticos ou com grupos, mas que apenas tenha como norteador em sua atividade a norma validamente existente” (2009, p. 132).
} _vol.09, no. 02, Rio de Janeiro, 2016.pp. 1155-1174 
técnica, amplamente reconhecida, entre nós, ao Ministério Público e à Defensoria Pública (também integrantes das chamadas "Funções Essenciais da Justiça"), assim como aos Tribunais de Contas (que auxiliam o Poder Legislativo no controle externo da atividadeadministrativa).

\section{A ADVOCACIA PÚBLICA COMO “ÓRGÃO CONSTITUCIONAL DE SOBERANIA".}

Apesar disso, não há sentido em se qualificar a Advocacia Pública, e tampouco a Defensoria Pública ou o Ministério Público, como um quarto poder. A propósito, Maria Sylvia Zanella Di Pietro leciona que conquanto a Constituição não as tenha colocado "dentro de um ou outro dos Poderes do Estado", alçando-as, com isso, ao "mesmo nível daqueles, englobando-as num bloco único, quase como se constituíssem um quarto poder" dentro do título consagrado aos Poderes da República (Título IV), "isso não significa que exista um quarto poder", embora permita "inferir que as funções ali referidas são do mesmo nível de importância que as desempenhadas pelos três Poderes do Estado" (1996, p. 13).

Como cediço, os Poderes da República inspiram-se na clássica tripartição de Montesquieu, que sedimenta a instituição de três Poderes, o Legislativo, o Executivo e o Judiciário, que hoje se caracterizam, conforme Diogo de Figueiredo Moreira Neto, "mais pela ênfase dada a certas funções que pela exclusividade de seu desempenho" (1991, p. 17). E tal se dá porque é imprecisa a afirmação de que o Poder Executivo somente desempenha função administrativa, de que o Poder Legislativo apenas realiza função legislativa e de que o Poder Judiciário exerce unicamente função jurisdicional. Tampouco se pode ter por fundada a suposição de que apenas o Executivo desempenha função administrativa, bem como de que somente o Judiciário e o Legislativo exercem, respectivamente, as funções legislativa e jurisdicional ${ }^{30}$.

Em vista disso, Anderson Sant'Ana Pedra expressa que "o que, geralmente, embora de forma equivocada, é muitas vezes designado como a separação dos poderes do Estado é, na verdade, a distribuição de determinadas funções estatais a diferentes órgãos" (2012, p. 223). Esse professor capixaba observa, então, reportando-se ao magistério de Hans Kelsen (2000, p. 390), que, quando se cogita do relacionamento entre as funções estatais a expressão distribuição é preferível à expressão separação, "justamente para que não se desenvolva a equivocada idéia de que uma separação busca uma segregação, um isolamento de cada uma das

\footnotetext{
${ }^{30}$ Conforme Celso Antônio Bandeira de Mello, "o critério adequado para identificar as funções do Estado é [...] aquele que se prende a características impregnadas pelo próprio Direito à função tal ou qual” (2010, p. 35). Nessa perspectiva, a função legislativa é aquela que o Estado "exerce por via de normas gerais, normalmente abstratas, que inovam inicialmente na ordem jurídica, isto é, que se fundam direta e imediatamente na Constituição”; a função jurisdicional, por sua vez, é aquela exercida "por via de decisões que resolvem controvérsias com força de "coisa julgada"; a a passo que a função administrativa é a função "que o Estado, ou quem lhe faça às vezes, exerce na intimidade de uma estrutura e regime hierárquicos", que se caracteriza, no regime constitucional brasileiro, "pelo fato de ser desempenhada mediante comportamentos infralegais ou, excepcionalmente, infraconstitucionais, submissos todos a controle de legalidade pelo Poder Judiciário” (Mello, 2010, p. 35-36). Sobre o assunto, ler também: Madureira, 2015, p. 106-132).
} vol.09, no. 02, Rio de Janeiro, 2016.pp. 1155-1174 
funções", quando "o objetivo da separação é outro; é um controle mútuo dos 'poderes" (Pedra, 2012, p. 223). Porém, embora considere mais adequado o emprego da expressão “distribuição de funções estatais", Pedra não vê equívoco na utilização da expressão "separação de poderes", contanto "que reste assentado que a expressão não está a externar um isolamento de cada uma das funções" (2012, p. 223). Neste contexto, "enquanto se mantiver a cláusula da separação de poderes como supedâneo do esquema de organização de poderes num determinado Estado (cláusula parâmetro)", será necessária a manutenção da delimitação de zonas de atuação independentes e harmônicas dos chamados "órgãos constitucionais de soberania" (Pedra, 2012, p. 224); qualificação proposta por José Joaquim Gomes Canotilho para distinguir determinados órgãos públicos que têm competências fixadas na Constituição, que dispõem de certo poder de auto-organização interna, que não estão subordinados a outros órgãos e que com eles estabelecem relações de interdependência e controle (2000, p.564).

Esse é o contexto em que se inserem, entre nós, as procuraturas constitucionais, compostas pelo Ministério Público, pela Advocacia Pública e pela Defensoria Pública, que contribuem, com relativa autonomia em relação aos Poderes da República, para o desempenho de funções estatais típicas. Seus membros auxiliam no exercício da função jurisdicional, na medida em que se qualificam como partícipes da atividade cognitiva desenvolvida pela comunidade de intérpretes, liderada pelo Poder Judiciário, com vistas à interpretação e aplicação do Direito (cf. Madureira, 2015, p. 101-102). No pormenor, assume especial relevância a atuação da Advocacia Pública, que além de coadjuvar a função jurisdicional (atividade contenciosa), interfere, ainda, no exercício da função administrativa ${ }^{31}$, quando atua na consultoria jurídica e no controle interno da juridicidade do agir administrativo. Além disso, quando se considera, num plano geral, que a iniciativa de lei (CRFB, art. 61, p. $1^{0^{32}}$ ) e o veto por inconstitucionalidade (CRFB, art. 66, p. $1^{033}$ ) integram a atividade legislativa, também a

\footnotetext{
${ }^{31}$ Como expus alhures, essa sua atividade é exercida preferencialmente no âmbito do Poder Executivo (inclusive nas autarquias, fundações públicas, empresas públicas e sociedades de economia mista), mas também pode ser estendida aos Poderes Legislativo e Judiciário, assim como ao Ministério Público, à Defensoria Pública e aos Tribunais de Contas (Madureira, 2015, p. 106-132).

${ }^{32}$ CRFB. "Art. 61. A iniciativa das leis complementares e ordinárias cabe a qualquer membro ou Comissão da Câmara dos Deputados, do Senado Federal ou do Congresso Nacional, ao Presidente da República, ao Supremo Tribunal Federal, aos Tribunais Superiores, ao Procurador-Geral da República e aos cidadãos, na forma e nos casos previstos nesta Constituição. $\$ 1^{\circ}$ _ São de iniciativa privativa do Presidente da República as leis que: I - fixem ou modifiquem os efetivos das Forças Armadas; II disponham sobre: a) criação de cargos, funções ou empregos públicos na administração direta e autárquica ou aumento de sua remuneração; b) organização administrativa e judiciária, matéria tributária e orçamentária, serviços públicos e pessoal da administração dos Territórios; c) servidores públicos da União e Territórios, seu regime jurídico, provimento de cargos, estabilidade e aposentadoria (Redação dada pela Emenda Constitucional no 18, de 1998); d) organização do Ministério Público e da Defensoria Pública da União, bem como normas gerais para a organização do Ministério Público e da Defensoria Pública dos Estados, do Distrito Federal e dos Territórios; e) criação e extinção de Ministérios e órgãos da administração pública, observado o disposto no art. 84, VI (Redação dada pela Emenda Constitucional no 32, de 2001); f) militares das Forças Armadas, seu regime jurídico, provimento de cargos, promoções, estabilidade, remuneração, reforma e transferência para a reserva (Incluída pela Emenda Constitucional no 18, de 1998)".

${ }^{33}$ CRFB. "Art. 66. A Casa na qual tenha sido concluída a votação enviará o projeto de lei ao Presidente da República, que, aquiescendo, o sancionará. $\$ 1^{\circ}$ - Se o Presidente da República considerar o projeto, no todo ou em parte, inconstitucional ou contrário ao interesse público, vetá-lo-á total ou parcialmente, no prazo de quinze dias úteis, contados da data do recebimento, e comunicará, dentro de quarenta e oito horas, ao Presidente do Senado Federal os motivos do veto”.
} vol.09, no. 02, Rio de Janeiro, 2016.pp. 1155-1174 
produção de manifestações jurídicas sobre a constitucionalidade dos textos legislativos aprovados pelo Parlamento (em orientação ao veto) e sobre os anteprojetos encaminhados às Casas Legislativas (em orientação à iniciativa de lei) correspondem, sob certa ótica, a uma sua participação no exercício da função legislativa.

Devo acrescentar, por derradeiro, que os serviços jurídicos que compõem a Advocacia Pública, (i) têm suas competências fixadas na Constituição, mais especificamente nos seus artigos 131 e 132, que a eles conferem o exercício das atividades de consultoria jurídica e contencioso judicial, bem como no seu artigo 70, do qual se infere a sua competência para realizar o controle interno da juridicidade do agir administrativo (cf. Madureira, 2015, p. 102-106); (ii) ostentam relativo poder de auto-organização interna, que lhes asseguram as suas respectivas leis orgânicas; (iii) não se encontram juridicamente subordinados a outros órgãos, por decorrência da independência técnica que é própria da atividade advocatícia (Lei no 9.806/1994, art. 7o, $\mathrm{I}^{34} \mathrm{e}$ art. 31, p. 1035) (cf. Madureira, 2015, p. 227-232); e por isso (iv) estabelecem relações de interdependência e controle com os poderes, órgãos e entidades que compõem o Estado Brasileiro.

Disso resulta a qualificação da Advocacia Pública como "órgão constitucional de soberania" (cf. Canotilho, 2000, p. 564), portanto como instituição que não se subordina, juridicamente, quer ao Poder Executivo, quer aos demais Poderes da República (cf. Madureira, 2015, p.223-226).

\section{CONCLUSÕES.}

Espero haver demonstrado, com essas considerações, que a Advocacia Pública não se qualifica como órgão do Poder Executivo, ou de qualquer outro Poder da República, dado o seu posicionamento na topografia do texto constitucional, que a situa, na designação proposta por Diogo de Figueiredo Moreira Neto, entre as procuraturas constitucionais (portanto, ao lado do Ministério Público e da Defensoria Pública), e dada a circunstância dela atender simultaneamente os Poderes Executivo, Legislativo e Judiciário, assim como o Ministério Público, a Defensoria Pública e os Tribunais de Contas (órgãos autônomos em relação ao Executivo), que lhe conferem a conotação de órgão constitucional de soberania, qualificação proposta por Canotilho para distinguir determinados órgãos públicos que têm competências fixadas na Constituição, que dispõem de certo poder de auto-organização interna, que não estão subordinados a outros órgãos e que com eles estabelecem relações de interdependência e controle.

\footnotetext{
${ }^{34}$ Lei 9.806. "Art. 7o São direitos do advogado: I - exercer, com liberdade, a profissão em todo o território nacional".

${ }^{35}$ Lei 8.906. "Art. 31. O advogado deve proceder de forma que o torne merecedor de respeito e que contribua para o prestígio da classe e da advocacia. $\$ 1^{\circ} \mathrm{O}$ advogado, no exercício da profissão, deve manter independência em qualquer circunstância”. vol.09, nº. 02, Rio de Janeiro, 2016.pp. 1155-1174
} 
Sua atuação se circunscreve, em rigor, sobre o exercício da função administrativa, não importando, nesse contexto, por que poder, órgão ou entidade essa função estatal é desempenhada ${ }^{36}$. São precisamente as atividades desempenhadas pelo Estado no contexto da execução da função administrativa que se encontram submetidas à atuação profissional dos advogados públicos quando desempenham as funções típicas que thes foram adjudicadas pelo constituinte. Assim, o Estado, no exercício de atos próprios da função administrativa, poderá formular questionamentos jurídicos à Advocacia Pública (atividade consultiva), bem como poderá chamá-la a representálo em caso de questionamento judicial de seus atos (atividade contenciosa). Num ou noutro âmbito, os advogados públicos devem informar aos gestores e demais agentes estatais que determinadas posturas adotadas pela Administração Pública mostram-se contrárias ao Direito, recomendando-lhes a sua revisão, sob a invocação dos princípios da legalidade administrativa, que a vincula, assim como a seus agentes, a uma correta aplicação do Direito (cf. Madureira, 2015, p. 34-38), e da indisponibilidade do interesse público e da supremacia do interesse público sobre o privado, inclusive sobre os chamados interesses particulares do Estado ${ }^{37}$ (cf. Madureira, 2015, p. $52-58)$.

O problema é que, pelas razões dantes expostas, não apenas o Poder Executivo (a quem a Advocacia Pública parece estar vinculada, pelo menos no plano administrativo) exerce função administrativa, também a desempenhando, ainda que residualmente, os Poderes Legislativo e Judiciário, bem como o Ministério Público, a Defensoria Pública e os Tribunais de Contas, que não se qualificam como poderes da República, mas certamente apresentam algum nível de autonomia em relação ao Executivo. Poderão exercê-las, ainda, as empresas públicas e as sociedades de economia mista, que são instituídas como pessoas jurídicas de direito privado, mas também praticam atos típicos de administração pública, porque se encontram submetidas, por exemplo, ao regime de licitações e contratos aplicáveis ao poder público (Lei no 8.666/1993, art. 1038) e à obrigatoriedade da realização de concursos públicos para contratação de pessoal (CRFB, art. 37, II ${ }^{39}$ ).

\footnotetext{
${ }^{36}$ Deve estar claro que não estou a afirmar, nesse ponto, que os procuradores desenvolvem atividades administrativas, ou de cunho executivo. Apenas atento à distinção que se faz em doutrina entre poderes e funções. Quanto ao particular, recobro o magistério de Celso Antônio Bandeira de Mello, expressado na seguinte passagem doutrinária: "Como se sabe, as funções legislativas, administrativas (ou executivas) e judiciais estão distribuídas, entre três blocos orgânicos, denominados "Poderes”, os quais, de regra, são explicitamente mencionados nas constituições modernas do Ocidente. Tais unidades orgânicas absorveriam, senão com absoluta exclusividade, ao menos com manifesta predominância, as funções correspondentes a seus próprios nomes: Legislativo, Executivo e Judiciário" (2010, p.30-31).

${ }^{37}$ Devo registrar, a propósito, que Celso Antônio Bandeira de Mello leciona que, ao lado do interesse público, por ele qualificado como "interesse do Estado e da sociedade na observância da ordem jurídica estabelecida" (2010, p. 72), o poder público também manifesta interesses particulares (por exemplo, cobrar tributos), designados por Renato Alessi (1960, p. 197) como interesses secundários e adiante qualificados por Bandeira de Mello como interesses individuais (ou particulares) do Estado (2010, p. 65-66). Para esse professor paulista, esses interesses particulares do Estado somente merecem proteção jurídica quando instrumentais ao interesse público (por exemplo, cobrar tributos dentro dos limites legais, para tornar viável o fornecimento de serviços públicos) (cf. Madureira, 2015, p. 52-58).

${ }^{38}$ Lei 8.666. "Art. 10 Esta Lei estabelece normas gerais sobre licitações e contratos administrativos pertinentes a obras, serviços, inclusive de publicidade, compras, alienações e locações no âmbito dos Poderes da União, dos Estados, do Distrito Federal e dos Municípios. Parágrafo único. Subordinam-se ao regime desta Lei, além dos órgãos da administração direta, os fundos especiais, as
} vol.09, nº. 02, Rio de Janeiro, 2016.pp. 1155-1174 
Todos esses poderes, órgãos e entidades são atendidos pela Advocacia Pública, que se qualifica, assim, como serviço jurídico concebido para atender ao Estado, quando considerado em seu sentido lato.

Essa constatação decorre de opções político-normativas encartadas no texto constitucional. Delas resulta a inconstitucionalidade das disposições legislativas editadas no âmbito da União, dos Estados e dos Municípios com o propósito de conferir aos dirigentes das procuradorias o status de Ministro (União) ou de Secretário (Estados e Municípios) $^{40}$. Delas decorre, ainda, que a Advocacia Pública não se apresenta como órgão subordinado à Chefia do Poder Executivo e por isso não tem a sua atuação marcada pela parcialidade referida pelo Ministro Ilmar Galvão por ocasião do julgamento da Ação Direta de Inconstitucionalidade no 470, que não se cogita da sua vinculação dos interesses defendidos pelo Chefe do Executivo, destacada pelo Ministro Morteira Alves no contexto da Ação Direta de Inconstitucionalidade no 291, e nem da relação de estrita confiança a que referiu o Ministro Sepúlveda Pertence nesse mesmo julgamento.

É que, em rigor, os advogados públicos mantêm (como qualquer advogado) plena liberdade e independência para manifestar seus posicionamentos jurídicos, e, como consequência delas, para interferir no modo como a Administração Pública se comportará nas relações que mantém com os administrados. Disso derivou, aliás, a distinção, pelo Supremo Tribunal Federal, a partir do julgamento da Ação Direta de Inconstitucionalidade no 470 (referida no capítulo introdutório), entre autonomia funcional e independência (ou autonomia técnica) da Advocacia Pública ${ }^{41}$ (cf. Madureira, 2015, p. 234-237). Além disso, o regime jurídico administrativo lhes impõe, como agentes estatais, posicionar-se em estrita conformidade com o Direito, dada a incidência dos princípios administrativos da legalidade, da supremacia do interesse público sobre o privado e da

autarquias, as fundaçoes públicas, as empresas públicas, as sociedades de economia mista edemaisentidades controladas direta ou indiretamente pela União, Estados, Distrito Federal e Municípios" (destaques pessoais).

${ }^{39}$ CRFB. "Art. 37. A administração pública direta e indireta de qualquer dos Poderes da União, dos Estados, do Distrito Federal e dos Municípios obedecerá aos princípios de legalidade, impessoalidade, moralidade, publicidade e eficiência e, também, ao seguinte: [... II - a investidura em cargo ou emprego público depende de aprovação prévia em concurso público de provas ou de provas e títulos, de acordo com a natureza e a complexidade do cargo ou emprego, na forma prevista em lei, ressalvadas as nomeações para cargo em comissão declarado em lei de livre nomeação e exoneração" (destaques pessoais).

${ }^{40}$ Recobro, a propósito, que é bastante comum, na legislação administrativa, o alinhamento da Advocacia Pública aos órgãos integrantes da sua Administração Direta, com a atribuição de prerrogativas de Ministros ou de Secretários de Estado aos seus dirigentes.

${ }^{41} \mathrm{~A}$ despeito de o pedido haver sido julgado procedente para efeito de declara a inconstitucionalidade do dispositivo da Constituição do Estado do Amazona que atribuiu autonomia funcional aos advogados públicos, também se reconheceu, em obter dictum (cf. Didier Jr., Braga e Oliveira, 2008; p. 350), que esses profissionais ostentam o que o Ministro Sepúlveda Pertence designou na oportunidade como autonomia profissional, que decorre da sua própria condição de advogados, a quem o ordenamento jurídico-positivo (Lei no 8.906/1994, art. $7^{\circ}$, I e art. 31, p. $1^{\circ}$ ) assegura a necessária independência técnica. O relator do processo, Ministro Ilmar Galvão, rejeitou a extensão dessa prerrogativa aos advogados públicos, reportando-se, na fundamentação de seu Voto, ao posicionamento firmado pelo Ministro Sepúlveda Pertence quando da concessão da Medida Cautelar na Ação Direta de Inconstitucionalidade no 291 (julgamento igualmente mencionado no capítulo introdutório). Ocorre que, nesse novo processo, o Ministro Pertence, aderindo à objeção levantada pelo Ministro Marco Aurélio, abrandou o seu entendimento sobre o tema. Com efeito, para além de dispor que os procuradores não possuem autonomia funcional (tal como conferida pela Constituição ao Ministério Público), condição que os conduziria, por exemplo, "à possibilidade, sem autorização de seus superiores, de reconhecer o direito posto em juízo", Pertence admitiu que eles ostentam autonomia profissional (ou autonomia técnica, como prefiro chamar), que decorre da sua própria condição de advogados (cf. Madureira, 2015, p. 233-243). 
indisponibilidade do interesse público (cf. Madureira, 2015), esses últimos conformados pela observação de Celso Antônio Bandeira de Mello quanto a corresponder o interesse público ao "interesse do Estado e da sociedade na observância da ordem jurídica estabelecida" (2010, p. 73). Mas isso é assunto para ser discutido em outros trabalhos.

\title{
PUBLIC LAW: STATE BOARD OR THE EXECUTIVE POWER?
}

\begin{abstract}
This work aims to demonstrate that public prosecutors are not presented as organs of the executive power, qualifying, in fact, rather, as State bodies, considered in the broadest sense of the term. In furtherance of this, the inception of Public Advocacy in the Brazilian state organization and the specification of powers conferred to it by each of the constituent public institutions that comprise the list of the so-called essential functions of justice, to discuss the inherent difficulties found in the appointment of public prosecutors as organs subordinate to the executive branch and the consequent need for their qualification as constitutional organs of sovereignty. The confirmation of the thesis according to which Public Advocacy transcends the structure of the executive branch, to be set up as an organ of the State, refutes the implication (harvested from legal praxis) that its members would be forced to seek the conference of the appearance of legality of the political and administrative options preconceived by those governing and other public officials, and thus provide more effective internal control of administrative activity.
\end{abstract}

Keywords: Right. Constitutional Law. Administrative Law. Public Advocacy. Constitutional Organs of Sovereignty.

\section{REFEREANCIAS BIBLIOGRÁFICAS.}

ALESSI, Renato. Sistema instituzionale del diritto amministrativo italiano. 3 ed. Milão: Giuffrè, 1960.

BASTOS, Celso Ribeiro; MARTINS, Ives Gandra. Comentários à Constituição do Brasil, t. IV. São Paulo, 1997.

CANOTILHO, José Joaquim Gomes. Direito Constitucional e Teoria da Constituição. 7a ed. Coimbra: Almedina, 2000.

CARPES, Marcus Ronald. "Advocacia da União e Estado de Justiça”. In: GUEDES, Jefferson Carús; SOUZA, Luciane Moessa de (Coord.). Advocacia de Estado: questões institucionais para a construção de um Estado de justiça. Belo Horizonte: Fórum, 2009.

CARVALHO, Juan Pablo Couto de. "Advocacia-Geral da União: breve relato do maior escritório de advocacia do país”. In: GUEDES, Jefferson Carús; SOUZA, Luciane Moessa de (Coord.). Advocacia de Estado: questões institucionais para a construção de um Estado de justiça. Belo Horizonte: Fórum, 2009.

DI PIETRO, Maria Sylvia. "Advocacia Pública”. Revista Jurídica da Procuradoria Geral do Município de São Paulo, São Paulo, n. 3, p. 11-30, dez 1996.

Direito Administrativo. 13ª ed. São Paulo: Atlas, 2001. 
DIDIER JÚNIOR, Fredie, BRAGA, Paula Sarno e OLIVEIRA, Rafael. Curso de direito processo civil, v. 2. Salvador: Juspodivm, 2008.

FERREIRA, Sérgio D'Andréa. Comentários à Constituição, v.3. Rio de Janeiro: Freitas Bastos, 1991.

GRANDE JÚNIOR, Cláudio. "Advocacia pública: estudo classificatório de direito comparado". In: GUEDES, Jefferson Carús; SOUZA, Luciane Moessa de (Coord.). Advocacia de Estado: questões institucionais para a construção de um Estado de justiça. Belo Horizonte: Fórum,2009.

GUEDES, Jefferson Carús; SOUZA, Luciane Moessa de. "Apresentação". In: GUEDES, Jefferson Carús; SOUZA, Luciane Moessa de. Advocacia de Estado: questões institucionais para a construção de um Estado de justiça. Belo Horizonte: Fórum, 2009.

GUEDES, Jefferson Carús; SOUZA, Luciane Moessa de (Coord.). Advocacia de Estado: questões institucionais para a construção de um Estado de justiça. Belo Horizonte: Fórum, 2009.

KELSEN, Hans. Teoria Geral do Direito e do Estado. $3^{a}$ ed. Tradução de Luís Carlos Borges. São Paulo: Martins Fontes, 2000.

KIRCH, César do Vale. "A alavancagem da AGU para a consolidação e o sucesso da advocacia pública de Estado no Brasil”. In: GUEDES, Jefferson Carús; SOUZA, Luciane Moessa de (Coord.). Advocacia de Estado: questões institucionais para a construção de um Estado de justiça. Belo Horizonte: Fórum, 2009.

LEITE, Valdemar. Advocacia-Geral da União: instituição constitucional independente ou órgão do executivo? Monografia. Brasilia: IDP, 2003. p.93-94.

MACEDO, Rommel. Advocacia-Geral da União na Constituição de 1988. São Paulo: LTr, 2008. p. 161.

MADEIRA, Danilo Cruz. “O papel da Advocacia Pública no Estado Democrático de Direito". Revista Virtual da AGU, ano 10, n. 107, dez. 2010. Disponível em: <http://www.agu.gov.br/sistemas/site/TemplateImagemTextoThumb.aspx?idConteudo=152998\&id_site=11 $15 \&$ ordenacao $=1>$. Acesso em: 23 out. 2012.

MADUREIRA, Claudio. Advocacia Pública. Belo Horizonte: Fórum,2015.

Direito, processo e justiça: o processo como mediador adequado entre o direito e a justiça. Salvador: Juspodivm, 2013.

"Instituição de procuradorias jurídicas no âmbito dos Municípios: uma imposição constitucional". Revista Fórum Municipal e Gestão de Cidades, a. 2, n. 5, p. 28-39, maio/junho de2014.

MELLO, Celso Antônio Bandeira de. Curso de Direito Administrativo. 27a ed. São Paulo: Malheiros, 2010.

MITIDIERO, Daniel Francisco. Colaboração no processo civil: pressupostos sociais, lógicos e éticos. São Paulo: Revista dos Tribunais, 2009.

MOREIRA NETO, Diogo de Figueiredo. "As funções essenciais à justiça e as procuraturas constitucionais". Revista da Procuradoria Geral do Estado de São Paulo, dez. 1991. 
MOURÃO, Carlos Figueiredo. "A advocacia pública como instituição de controle interno da administração". In: GUEDES, Jefferson Carús; SOUZA, Luciane Moessa de (Coord.). Advocacia de Estado: questões institucionais para a construção de um Estado de justiça. Belo Horizonte: Fórum, 2009.

PEDRA, Anderson Sant 'Ana. "O Tribunal Constitucional e o exercício da função legislativa stricto sensu para a efetivação dos direitos fundamentais em decorrência de uma omissão legislativa inconstitucional”. Revista de Direitos e Garantias Fundamentais, Vitória: Faculdade de Direito de Vitória, n. 11. Disponível em: <http://www.fdv.br/sisbib/index.php/direitosegarantias/article/view/161/129>. Acesso em: 29 out. 2012.

SESTA, Mario Bernardo. "Advocacia do Estado: posição institucional”. Revista de Informação Legislativa, v. 30, n. 117, jan./mar. 1993.

TORRES, Ronny Charles Lopes de. "A responsabilidade do Advogado de Estado em sua função consultiva". In: GUEDES, Jefferson Carús; SOUZA, Luciane Moessa de (Coord.). Advocacia de Estado: questões institucionais para a construção de um Estado de justiça. Belo Horizonte: Fórum,2009.

VALENTE, Maria Jovita Wolney. "Histórico e evolução da Advocacia-Geral da União". In: GUEDES, Jefferson Carús; SOUZA, Luciane Moessa de (Coord.). Advocacia de Estado: questões institucionais para a construção de um Estado de justiça. Belo Horizonte: Fórum,2009.

Trabalhoenviadoem05dedezembrode2015.

Aceitoem 12 dejaneiro de2016. 